

Erfani, R., Zare-B ehtash, H., and K ontis, K. (2012) Plasma actuator: influence of dielectric surface temperature. Experimental Thermal and Fluid Science, 42 . pp. 258-264. ISSN 0894-1777

Copyright $\odot 2012$ Elsevier

A copy can be downloaded for personal non-commercial research or study, without prior permission or charge

Content must not be changed in any way or reproduced in any format or medium without the formal permission of the copyright holder(s)

When referring to this work, full bibliographic details must be given

http://eprints.gla.ac.uk/84620/

Deposited on: 19 M ay 2014

Enlighten - Research publications by members of the U niversity of Glasgow http://eprints.gla.ac.uk 


\title{
Plasma Actuator: Influence of Dielectric Surface Temperature
}

\author{
R. Erfani, H. Zare-Behtash, and K. Kontis* \\ Aero-Physics Laboratory, School of Mechanical, \\ Aerospace and Civil Engineering, University of Manchester, UK
}

\begin{abstract}
Plasma actuators have become the topic of interest of many researchers for the purpose of flow control. They have the advantage of manipulating the flow without the need for any moving parts, a small surface profile which does not disturb the free stream flow, and the ability to switch them on or off depending on the particular situation (active flow control). Due to these characteristics they are becoming very popular for flow control over aircraft wings. The objective of the current study is to examine the effect of the actuator surface temperature on its performance. This is an important topic to understand when dealing with real life aircraft equipped with plasma actuators. The temperature variations encountered during a flight envelope may have adverse effects in actuator performance. A peltier heater along with dry ice are used to alter the actuator temperature, while particle image velocimetry (PIV) is utilised to analyse the flow field. The results show a significant change in the induced flow field by the actuator as the surface temperature is varied. It is found that for a constant peak-to-peak voltage the maximum velocity produced by the actuator depends directly on the dielectric surface temperature. The findings suggest that by changing the actuator temperature the performance can be maintained or even altered at different environmental conditions.
\end{abstract}

Keywords: Plasma actuator, Dielectric Barrier Discharge






\section{INTRODUCTION}

There are various classes of actuators derived from the class of electrical discharge such as: direct discharge, microwave discharge, DBD, corona discharge, spark, etc. ${ }^{1,2}$ In the past ten years single dielectric barrier discharge (SDBD) actuators have shown remarkable promise for various flow control applications. The benefit of converting electrical energy into kinetic energy without the need for any moving parts, having near instantaneous response, consuming relatively low power, and a wide range of operational frequencies have made these devices an attractive alternative to other active flow control methods such as piezoelectric actuators, synthetic jets, and vortex generators. ${ }^{3}$ A new kind of surface plasma called OAUGDP ${ }^{T M}$ was introduced by Roth et al. ${ }^{4}$ Their investigations showed the ability of the new configuration of plasma actuator in changing drag and varying the thrust direction of flat panels ${ }^{5}$ and re-attachment of flow in a NACA 0015 aerofoil. ${ }^{6}$ Furthermore, the actuator can be operated at atmospheric pressures and does not require a sophisticated power supply. SDBDs have the ability to manipulate the boundary layer, ${ }^{7-11}$ film cooling ${ }^{12}$ and delaying separation on turbine blades ${ }^{13}$ and aerofoils, ${ }^{14}$ and manipulate the transition point, ${ }^{15}$ control separation on stationary ${ }^{16}$ and oscillating aerofoils ${ }^{17}$ leading to reduced noise levels. ${ }^{18}$ However, to date, they have only been used at micro air vehicle Reynolds numbers (e.g., on small unmanned aircraft $\left.{ }^{19,20}\right)$. Their benefits have not been fully utilised on large scales since the effectiveness of plasma actuators is limited by the maximum induced velocity they can achieve.

The SDBD consists of a linear asymmetric arrangement of two electrodes separated by a dielectric material. One electrode is exposed to the air, while the other is encapsulated in the dielectric. ${ }^{21,22}$ The electrodes are long and thin and are arranged spanwise on an aerodynamic surface. A high voltage alternating current (AC) input, with typical voltages of $2 \mathrm{kV}$ to $40 \mathrm{kV}_{p-p}$ (peak to peak) and frequencies of $300 \mathrm{~Hz}$ to $1 \mathrm{MHz}$ are supplied to the exposed electrode while the encapsulated electrode is grounded. Such a high potential difference weakly ionizes the surrounding gas over the hidden electrode.

Using plasma actuators in aviation as a flow control device and internal flow applications ${ }^{23}$ in gas turbine engines ${ }^{24}$ will result in the actuators being exposed to many environmental temperatures. This makes the examination of the effect of temperature necessary to fully characterise plasma actuator performance. ${ }^{25-27}$ Segawa et al. ${ }^{27}$ showed a decrease in performances of circular plasma actuators by increasing the temperature of the surrounding. 
Schlieren photography was employed to monitor the deflection of a $\mathrm{CO}_{2}$ tracer jet by the DBD wall normal jet. Versailles et al. ${ }^{25}$ implemented force measurements on the conventional SDBD actuator and observed that the induced force on the fluid increases almost linearly with increasing the surrounding temperature. This paper presents results of an experimental study of the induced jet of a single dielectric barrier discharge under three different temperatures, at atmospheric pressure. The temperature of the dielectric surface was varied directly as opposed to changing the environmental temperature, as has been the case in previous studies.

\section{EXPERIMENTAL SETUP}

\section{A. Plasma generation and power measurements}

A schematic illustration of the actuator is shown in Figure 1. The electrodes are made of $74 \mu \mathrm{m}$-thick tinned copper foil tape, and $100 \mathrm{~mm}$ in length. The widths of exposed and hidden electrodes are 3 and $40 \mathrm{~mm}$, respectively. Layered Kapton tape (with each layer having a $60 \mu \mathrm{m}$ thickness) was used as a dielectric material with the total thickness of 300 $\mu \mathrm{m}$. The actuators are mounted on a Perspex substrate.

An 8-channel Multiphase high-voltage generator by Electrofluid Systems is used to generate voltages up to $10 \mathrm{kV}_{p-p}$ and frequencies up to $20 \mathrm{kHz}$. The circuit board is monitored via National Instruments (NI) Data Acquisition device (DAQ) by means of the LabView program working as an oscilloscope. A LeCroy 1:1000 high voltage probe, calibrated up to $40 \mathrm{kV}$ peak has been used for input voltage monitoring while the current output is monitored using a Tektronix current probe. Data was collected at a rate of $100 \mathrm{MHz}$. A high bandwidth oscilloscope was necessary to record the plasma discharge due to the high frequency nature of the discharge events. Both the voltage and current probes are connected to a Picoscope 3206, $200 \mathrm{MHz}$ digital oscilloscope and the signals are recorded onto a PC terminal. The input voltage supplied to the exposed electrode has been varied from $2 \mathrm{kV}_{p-p}$ up to $8 \mathrm{kV}_{p-p}$ while the frequency is kept constant at $10 \mathrm{kHz}$. This driving frequency gave a pure sinusoidal input waveform. 


\section{B. Particle image velocimetry}

Particle image velocimetry (PIV) uses the displacement of particles to determine various flow field parameters. A laser beam is manipulated into a thin sheet using an arrangement of lenses to illuminate the region of interest. Figure 2 shows a schematic of the experimental setup. Using two successive laser pulses separated by a known time, statistical analysis can be performed to measure the instantaneous velocity of the tracer particles captured with a high-speed camera. The PIV measurements were performed using a LaVision system with an NDYAG 532/1064 nm, Litron $200 \mathrm{~mJ}$, pulsed laser. The laser pulsed with a repetition rate of $15 \mathrm{~Hz}$, and a pulse width of $4 \mathrm{~ns}$. In these experiments the duration between pulses was set at $700 \mu \mathrm{s}$. This value is set based on the field of view size and expected induced velocity, of the order of $1 \mathrm{~m} / \mathrm{s}$. The laser was delivered using a laser arm mounted above the actuator to produce a laser sheet that ran along the centre-line of the actuator span, normal to the electrodes. The actuator was located in a sealed chamber were seeding was introduced using a 6 jet atomizer that produced light-scattering olive oil particles with a size of approximately $1 \mu \mathrm{m}$. After the chamber was filled with particles the seeding was stopped and the particles were allowed to reach a quiescent state before commencing the experiments.

\section{Temperature variation and control}

For cooling and heating the surface temperature of the actuator to $-40^{\circ} \mathrm{C}$ and $120^{\circ} \mathrm{C}$, dry ice and a peltier heater were used, respectively. To achieve a uniform temperature over the surface, in the hot-case, the actuator was placed on top of the peltier heater. By changing the voltage supplied to the peltier the temperature was varied until the desired value was reached. In the cold-case, the actuator was put in a dry ice fridge immediately before doing each set of experiments. The time interval between removing the actuator from the dry ice fridge and placing it within the PIV chamber was approximately 10 seconds. The actuator was switched on for 5 seconds to reach stable run time before commencing the PIV measurements which lasted for approximately 6 seconds. Using thermocouples placed at different positions along the dielectric surface the uniformity of the temperature distribution was continuously monitored before conducting the experiments and the creation of the plasma strip (see 
Figure 1 for thermocouple locations). This ensured no electrical interference and eliminated the chances of sparking between the thermocouple probe and the exposed electrode. The surface temperature was recorded after each run and was found to be within $\pm 1.5^{\circ} \mathrm{C}$ and $\pm 1^{\circ} \mathrm{C}$ of the initial conditions for the cold and hot cases, respectively. When performing repeats of each temperature case, it was ensured that the initial temperature was identical to the previous case tested.

The hot and cold cases were performed on different days so that the actuator could return to ambient conditions over night.

\section{RESULTS AND DISCUSSION}

Figure 3 compares the voltage and current graphs of the standard SDBD at different temperatures for $8 \mathrm{kV}_{p-p}$ and $10 \mathrm{kHz}$. The ambient, cold, and hot labels in the figures refer to temperatures of: $20^{\circ} \mathrm{C},-40^{\circ} \mathrm{C}$, and $120^{\circ} \mathrm{C}$, respectively. The consistent repeatability of the input voltage to the actuator in different temperatures is illustrated in Figure 3(a). However, the current trace varies depending on the dielectric surface temperature. The current peaks such as those visible in Figure 3(b) are due to the presence of the microdischarges, and correspond to the creation of plasma. The number of discharges present in the figure does not appear to change with increasing temperature, however, the magnitude of the peaks increases. It is believed that by having stronger microdischarges deposited on the surface, the momentum coupling between the plasma and the neutral air increases leading to a faster induced jet as will be shown in the following sections. Based on the current and voltage measurements, the power consumption by the actuator is calculated using Eq.(1), where T and $\mathrm{N}$ represent the time period and the number of cycles, respectively.

$$
\text { Power }=\frac{1}{N T} \int_{N T} V(t) \cdot I(t) d t
$$

The effect of dielectric temperature on actuator power consumption for the range of voltages is depicted in Figure 5. The lines in the figure represent the power law fit in the form of $f(x)=a x^{b}$ similar to that used by Enloe et al. ${ }^{28}$ It can be seen that at lower temperatures less power is consumed by the actuator and at high voltages, the power consumption of the hot case is slightly more than that of the ambient case.

The percentage of power consumption variation at different surface temperatures is listed in 
Table I. Temperature appears to have a direct effect on the power consumption. The cold case uses less power with respect to the ambient case, and the high surface temperature uses slightly more power than the ambient case which, as it will be illustrated, makes them more favourable for flow control applications. It is also observed that decreasing the temperature reduces the uniformity as well as the size of the plasma, see Figure 4.

The dielectric power loss is given by Eq. $(2)^{29}$ where $A$ is the electrode area, $S$ is the electrode thickness, $f$ is the frequency of the applied voltage, $P$ is the dielectric power loss, $\tan \delta$ is the loss tangent of the dielectric material, $V_{r m s}$ is the root-mean-square voltage across the dielectric, and $\epsilon_{0}, \epsilon_{r}$ are the free space and relative permittivity of the dielectric material, respectively. For Kapton the values of the individual terms are provided by Roth and Dai. ${ }^{6}$ Therefore, the dielectric power loss of the actuator is calculated as $0.56 \mu \mathrm{W}$.

$$
P_{\text {loss }}=V_{r m s}^{2} \frac{2 \pi f A}{S} \epsilon_{r} \epsilon_{0} \tan \delta
$$

\begin{tabular}{ccc}
\hline $\mathrm{kV}_{p-p}$ & Hot respect to Ambient & Cold respect to Ambient \\
\hline 6 & 154.2 & -44.9 \\
7 & 8.0 & -65.7 \\
8 & 6.1 & -54.9 \\
\hline
\end{tabular}

TABLE I: Percentage change of power consumption with dielectric surface temperature

\section{A. Velocity contours}

Because of the reduction in density as a result of increasing temperature close to the surface, buoyancy effect reduces as well. Therefore, seeding particles tend to move towards the surface. To determine the effect of surface temperature on seeding particle distribution, i.e. the buoyancy, measurements within the seeded PIV chamber were taken when the actuator was off, for the highest temperature case $\left(120^{\circ} \mathrm{C}\right)$ the maximum velocity magnitude obtained was in the order of $0.06 \mathrm{~m} / \mathrm{s}$. This value is $0.05 \mathrm{~m} / \mathrm{s}$ for the cold case $\left(-40{ }^{\circ} \mathrm{C}\right)$. These are relatively small compare to the velocity of the induced jet $(1.5 \mathrm{~m} / \mathrm{s}$ and $0.6 \mathrm{~m} / \mathrm{s}$, respectively) when the actuator is switched on.

The velocity fields from which the velocity profiles were taken are shown in Figure 6 for an input signal of $10 \mathrm{kHz}$ and $8 \mathrm{kV}_{p-p}$. The interface of the exposed/encapsulated electrode 
is located at the $\mathrm{x}=0 \mathrm{~mm}$ position. With increasing temperature the high velocity region at the edge of the exposed electrode increases in size and magnitude. For all the cases studied, an induced jet flows across the encapsulated electrode. The jet core position (the region where the velocity is highest) moves further downstream over the encapsulated electrode. As it can be seen in Figure 6, by increasing the dielectric surface temperature, the velocity magnitude increases. A lower temperature between the particles and the dielectric surface can lead to the generation of a less uniform plasma in addition to a lower induced velocity. The inclination of the streamlines around the jet also changes from case to case. The angle between the induced jet and entrained flow rises with increasing temperature, as shown in the figure. This is due to the strength of the jet which creates a pressure difference. With increasing temperature, the strength of the induced flow rises, leading to a greater pressure difference and hence, a larger angle.

The streamlines follow different paths around the zero coordinate for the different cases. Based on the velocity field recorded, the circulation is calculated using Green's Theorem, $\Gamma=$ $\oint_{c}(u d x+v d y),{ }^{30}$ around a circuit, c, localised at the zero location. The circuit encompasses an area $5 \mathrm{~mm}$ from the actuator surface and $\pm 2.5 \mathrm{~mm}$ from the zero location. This insures that the flowfield characteristics around the exposed electrode are fully captured. The circulation increases from 0.35 to $0.49 \mathrm{~m}^{2} / \mathrm{s}$ by raising the temperature. It is because of the increase in vertical suction at high temperature that increases the rotation tendency of the particles. Also, since the circuit which the circulation is calculated is kept constant, the increase in circulation is indicative of the increase in area affected by the suction at the zero location.

\section{B. Velocity Profiles}

According to the definition of Froude number, $\mathrm{Fr}=V^{2} / L g,{ }^{31}$ the inertial force which depends on the induced velocity is different for different temperature cases while the force of gravity remains constant. Therefore, in this section the focus is on the induced velocity. The velocity profiles for the U-component of velocity are presented in Figure 7. These are for x-positions along the hidden electrode starting from the downstream edge of the exposed electrode and are extracted from the PIV velocity fields shown in Figure 6. At the downstream edge of the exposed electrode except for the cold case, the others produce 
an induced jet flowing from the exposed electrode across the encapsulated electrode, Figure 7(a). The induced jet for the cold case is very weak at this position. All of the cases show an increase in jet velocity $10 \mathrm{~mm}$ downstream of the exposed electrode, Figure $7(\mathrm{~b})$. The magnitude and thickness of the jet increase as the distance from the exposed electrode increases. The maximum velocity magnitude occurs between $\mathrm{x}=15$ and $20 \mathrm{~mm}$ for all three cases although their values are different for each case. After this region, at $\mathrm{x}=30 \mathrm{~mm}$, the velocity magnitude drops and the jet moves away from the surface.

To provide a clearer view of what is happening near the wall region, at $2 \mathrm{~mm}$ above the surface, the profiles along the $\mathrm{x}$-axis of the $\mathrm{U}$ - and $\mathrm{V}$-components of velocity are shown in Figures $8(\mathrm{a})$ and $8(\mathrm{~b})$, respectively. The U-component of velocity profiles provides a good indication of the region where the plasma couples momentum into the flow, increasing the velocity of the induced jet. For all the different actuator cases there is an almost linear growth of the velocity with x-position.

Immediately upstream of the exposed electrode there is a slight negative flow of velocity in the $\mathrm{x}$-direction occurring because of the airflow attracting towards the zero position. This magnitude is less for the cold case. The highest magnitude of the induced jet is produced by the hot case where the U-component of velocity can be seen to continue increasing along the encapsulated electrode (at $\mathrm{x}=20 \mathrm{~mm}$ ). For all cases, the maximum induced velocity occurs before the end of the encapsulated electrode, suggesting that the encapsulated electrode can be made shorter whilst achieving the same velocity.

Examining the $\mathrm{V}$-component for all cases the maximum magnitude of velocity occurs in close proximity to the downstream edge of the exposed electrode, this is reflected in the stream lines of Figure 6 . The density measurements of Enloe et al. ${ }^{32}$ at the downstream edge of the exposed electrode also showed a pressurised region in this vicinity. This establishes a pressure gradient that directs the pressure force in the downstream direction. The Vcomponent remains negligible outside of this narrow region.

Figure 9 shows the average velocity of the three runs each with 100 PIV image pairs, recorded at a constant frequency of $10 \mathrm{kHz}$. The error bars correspond to maximum variation in velocity recorded for the different image pairs. The greatest variation in velocity is estimated to be $\pm 0.13 \mathrm{~m} / \mathrm{s}$, for the cold case. This indicates the convergence in velocity. The Hot case shows higher values of induced velocity for each voltages and it can be seen that the induced velocity exhibits an increasing value with increasing temperature. 


\begin{tabular}{ccc}
\hline $\mathrm{kV}_{p-p}$ & Hot respect to Ambient & Cold respect to Ambient \\
\hline 6 & 23.1 & -74.4 \\
7 & 28.6 & -71.4 \\
8 & 45.5 & -43.0 \\
\hline
\end{tabular}

TABLE II: Percentage change of maximum velocity magnitude with dielectric surface temperature

Table II compares the variation of induced velocity for the various temperatures examined. Increasing the dielectric temperature can lead to higher induced velocities over a range of voltages. As it can be seen, at the maximum voltage in this experiment, $8 \mathrm{kV}_{p-p}$, the hot case increases the induce velocity of the jet by $45.5 \%$ in comparison to the ambient case.

By increasing temperature dynamic viscosity, $\mu$, and density, $\rho$, of air increases and decreases respectively. As a result, Reynolds number of the jet based on the maximum velocity, temperature of the surface and length of the actuator for cold and hot cases are 2950 and 3200 which shows that we have laminar boundary layer. The Prandtl number corresponding to the temperature range is between 0.7 and 0.72 , for the hot and cold cases, respectively. Therefore, the thermal boundary layer, $\delta_{t}(x)$, can be calculated from Eq. (3) as $0.102 x$ and $0.097 x$ for the cold and hot cases, respectively, where $x$ is the distance from the interface of the exposed and encapsulated electrodes. ${ }^{33}$

$$
\frac{\delta_{t}}{x}=\frac{4.916}{R e^{1 / 2} \operatorname{Pr}^{1 / 3}}
$$

The momentum boundary layer can be derived from Eq. (4) as $0.087 x$ and $0.09 x$ for the cold and hot cases.

$$
\frac{\delta_{m}}{x}=\frac{4.916}{R e^{1 / 2}}
$$

Therefore, in this low range of the Prandtl number the momentum boundary layer is thinner than the thermal boundary layer.

Since the electron deposition and ion movements happen in the presence of thermal boundary layer, the mean free path, $\lambda$, of the particles increases and air density reduces by increasing the temperature. This causes the charged particles to have more kinetic energy when they collide. Therefore, they can transfer more momentum to the neutral background air causing the increase in velocity magnitude of the jet. In addition, preheating of the 
ambient air close to the surface reduces the air density leading to a reduced air resistance which facilitates electron deposition, promotes easier air ionisation, and increases momentum transfer collision rates. ${ }^{34-36}$

This result is consistent with the results of Versailles et al. ${ }^{25}$ which observed the influence of surrounding temperature on the induced force. They examined the plasma actuator at high environmental temperatures between 30 and $200^{\circ} \mathrm{C}$ (rather than surface) for input voltages of $13-20 \mathrm{kV}_{p-p}$ at an actuator frequency of $9.4 \mathrm{kHz}$ and observed that the induced force on the fluid increases almost linearly with increasing temperature while increasing pressure, which leads to the increase in density, reduces the body force.

\section{Body Force Calculations}

From a flow dynamic perspective and to judge the performance of the actuator, the change in momentum is of primary interest. In order to assess this, the body force acting on the air can be calculated from the velocity profiles, Figure 7, using the momentum, $\sum \vec{F}=\oiint \vec{V}(\rho \vec{V} \cdot \hat{n} d A)$, and continuity equations, $\oiint_{A}(\rho \vec{V} \cdot \hat{n} d A)=0$, for the control volume. ${ }^{37}$

Two control volumes are analysed both beginning $10 \mathrm{~mm}$ upstream of the interface of the exposed and encapsulated electrodes and extend $20 \mathrm{~mm}$ above the surface. The first control volume (CV1) terminates $15 \mathrm{~mm}$ downstream of the interface of the exposed and encapsulated electrodes, and the second (CV2) terminates at $30 \mathrm{~mm}$. The $15 \mathrm{~mm}$ and 30 $\mathrm{mm}$ locations correspond to the same locations where velocity profiles were taken in Figure 7.

The forces acting on the control volume are: the body force, $F_{b}$, the wall shear force, $F_{s}$, and the pressure force, $F_{p}$. After expanding the momentum and continuity equations for the two cases of 'actuator on' and 'actuator off' and subtracting each set of equations from each other, we can combine the final two equations to arrive at equation Eq. (5) where $\delta$ is the height of the boundary layer, $u_{\infty}$ is the freestream velocity, and the subscript $d$ denotes the downstream location.

$$
\begin{aligned}
\left(F_{b, o n}-F_{b, o f f}\right)=( & \left.F_{s, o f f}-F_{s, o n}\right)+\left(F_{p, o f f}-F_{p, o n}\right) \\
& \quad-\rho u_{\infty} \int_{0}^{\delta}\left(u_{d, o n}-u_{d, o f f}\right) d y+\rho \int_{0}^{\delta}\left(u_{d, o n}^{2}-u_{d, o f f}^{2}\right) d y
\end{aligned}
$$




\begin{tabular}{lcc|cc} 
& \multicolumn{2}{c|}{ CV1 } & \multicolumn{2}{c}{ CV2 } \\
\cline { 2 - 5 } & $F_{b}[\mathrm{mN} / \mathrm{m}]$ & change $(\%)$ & $F_{b}[\mathrm{mN} / \mathrm{m}]$ & change $(\%)$ \\
\hline Ambient & 1.6 & - & 2.2 & - \\
Cold & 0.6 & -62.1 & 1.3 & -40.4 \\
Hot & 3.1 & 91.0 & 3.3 & 52.6 \\
\hline
\end{tabular}

TABLE III: Body force and percentage change with respect to the ambient case

Noting that the pressure force does not change in both cases and considering the fact that air is still when the actuator is off, after some simplifications $\left(F_{b, o f f}=F_{s, o f f}=0\right.$, $F_{p, o f f}=F_{p, o n}, u_{d, o f f}=0$ ) and using the equation for the change of shear stress, the body force can be calculated using Eq. (6).

$$
F_{b}=-\left.\mu \frac{d u}{d y}\right|_{y=0}+\rho \int_{0}^{\delta}\left(u_{d}^{2}\right) d y
$$

Table III summarises the calculated body forces for different temperature cases and the percentage variation of the body force respect to the ambient case. The increase of momentum for CV2 is due to the increase of jet height at the right hand boundary of the control volume located at $\mathrm{x}=30 \mathrm{~mm}$, even though the velocity of the jet at this location is reduced. The findings show a general trend of increasing body force with increasing actuator surface temperature.

\section{CONCLUSIONS}

Plasma actuators are promising devices in the field of active flow control due to their associated benefits they encompass. They have been subject of much attention by the plasma research community over the past few years. Application of such actuators as a means of flow control in aviation and turbomachinery makes the examination of the effect of environmental temperatures necessary to fully characterise actuator performance. In this research the maximum induced velocity has been measured by PIV measurement. The influence of voltage and temperature on the induced velocity were investigated. It has been depicted that with a hotter surface of the actuator we can have higher velocities and also

higher body forces by consuming only slightly higher power. Therefore, performance of the 
actuator can be increased by using a source of heat beneath it. The maximum induced velocity that the hot actuator could achieve was $45.5 \%$ higher than the baseline case while requiring $6.1 \%$ more power. The power consumption of the cold dielectric actuator was $54.9 \%$ lower than the baseline case while inducing a velocity $43 \%$ lower. As a result, increasing dielectric surface temperature can increase the plasma actuator performance by increasing the momentum flux whilst consuming slightly higher energy.

\section{Acknowledgments}

The authors are indebted to the technical and administrative staff at The University of Manchester for their assistance. The first author would also like to thank Dr. Tohid Erfani and Mr. Craig Hale for their technical advice. 
[1] E. Moreau. Airflow control by non-thermal plasma actuators. Journal of Physics D: Applied Physics, 40:605-636, 2007.

[2] J.S. Oh, O.T. Olabanji, C. Hale, R. Mariani, K. Kontis, and J.W. Bradley. Imaging gas and plasma interactions in the surface-chemical modification of polymers using micro-plasma jets. Journal of Physics D: Applied Physics, 44:155206, 2011.

[3] M. Gad-el Hak. Flow control: passive, active, and reactive flow management. Cambridge University Press, 2000.

[4] D.M. Roth, J.R. Sherman and S.P. Wilkinson. Boundary layer flow control with a one atmosphere uniform glow discharge surface plasma. In 36th Aerospace Sciences Meeting 8 Exhibit, Reno, Paper Number AIAA-1998-328, 1998.

[5] J.R. Roth, H. Sin, R.C.M. Madhan, and S.P. Wilkinson. Flow re-attachment and acceleration by paraelectric and peristaltic electrohydrodynamic (EHD) effects. In 41st AIAA Aerospace Sciences Meeting 83 Exhibit, Reno, Paper Number AIAA-2003-531, 2003.

[6] J.R. Roth and X. Dai. Optimization of the aerodynamic plasma actuator as an electrohydrodynamic (EHD) electrical device. In 44th AIAA Aerospace Sciences Meeting and Exhibit, Reno, Paper Number AIAA-2006-1203, pages 9-12, 2006.

[7] C. Porter, T. McLaughlin, C. Enloe, G. Font, J. Roney, and J. Baughn. Boundary Layer Control Using a DBD Plasma Actuator. In 45th AIAA Aerospace Sciences Meeting and Exhibit, Reno, Paper Number AIAA-2007-786, 2007.

[8] D.F. Opaits, D.V. Roupassov, S.M. Starikovskaia, A.Y. Starikovskii, I.N. Zavialov, and S.G. Saddoughi. Plasma control of boundary layer using low-temperature non-equilibrium plasma of gas discharge. AIAA Journal, 1180(43):10-13, 2005.

[9] I.G. Boxx, R.B. Rivir, J.M. Newcamp, and N.M. Woods. Reattachment of a separated boundary layer on a flat plate in a highly adverse pressure gradient using a plasma actuator. In $3 r d$ AIAA Flow Control Conference, San Francisco, Paper Number AIAA 2006-3023, 2006.

[10] J. Jacob, R. Rivir, C. Carter, and J. Estevadeordal. Boundary layer flow control using AC discharge plasma actuators. In AIAA 2nd Flow Control Meeting, Paper Number AIAA-20042128, volume 2128, 2004.

[11] G.I. Font. Boundary layer control with atmospheric plasma discharges. AIAA Journal, 
44(7):1572-1578, 2006.

[12] C.C. Wang and S. Roy. Electrodynamic enhancement of film cooling of turbine blades. Journal of Applied Physics, 104(7):073305, 2008.

[13] J. Huang, T.C. Corke, and F.O. Thomas. Plasma actuators for separation control of lowpressure turbine blades. AIAA Journal, 44(1):51-57, 2006.

[14] M.L. Post and T.C. Corke. Separation control on high angle of attack airfoil using plasma actuators. AIAA Journal, 42(11):2177-2184, 2004.

[15] S. Grundmann and C. Tropea. Delay of Boundary-Layer Transition Using Plasma Actuators. In 46th AIAA Aerospace Sciences Meeting and Exhibit, Paper Number AIAA-2008-1369, 2008.

[16] C. He, T.C. Corke, and M.P. Patel. Plasma flaps and slats: an application of weakly ionized plasma actuators. Journal of Aircraft, 46(3):864-873, 2009.

[17] M.L. Post and T.C. Corke. Separation control using plasma actuators: dynamic stall vortex control on oscillating airfoil. AIAA Journal, 44(12):3125-3135, 2006.

[18] F.O. Thomas, A. Kozlov, and T.C. Corke. Plasma actuators for cylinder flow control and noise reduction. AIAA Journal, 46(8):1921-1931, 2008.

[19] M.P. Patel, T.T. Ng, S. Vasudevan, T.C. Corke, and C. He. Plasma actuators for hingeless aerodynamic control of an unmanned air vehicle. Journal of Aircraft, 44(4):1264-1274, 2007.

[20] B. Goksel, D. Greenblatt, I. Rechenberg, R. Bannasch, and C.O. Paschereit. Plasma Flow Control at MAV Reynolds Numbers. In 3rd US-European Competition and Workshop on Micro Air Vehicle Systems and European Micro Air Vehicle Conference and Flight Competition, 2007.

[21] D.F. Opaits, A.V. Likhanskii, G. Neretti, S. Zaidi, M.N. Shneider, R.B. Miles, and S.O. Macheret. Experimental investigation of dielectric barrier discharge plasma actuators driven by repetitive high-voltage nanosecond pulses with dc or low frequency sinusoidal bias. Journal of Applied Physics, 104(4):043304, 2008.

[22] R. Erfani, T. Erfani, S.V. Utyuzhnikov, and K. Kontis. Optimisation of multiple encapsulated electrode plasma actuator. Aerospace Science and Technology, In Press, 2012.

[23] N. Benard, N. Balcon, and E. Moreau. Electric wind produced by a surface dielectric barrier discharge operating in air at different pressures: aeronautical control insights. Journal of Physics D: Applied Physics, 41:042002, 2008.

[24] H.D. Vo. Rotating stall suppression in axial compressors with casing plasma actuation. Journal of Propulsion and Power, 26(4):808-818, 2010. 
[25] P. Versailles, V. Gingras-Gosselin, and H.D. Vo. Impact of pressure and temperature on the performance of plasma actuators. AIAA Journal, 48:859-863, 2010.

[26] R. Erfani, C. Hale, and K. Kontis. The Influence of Electrode Configuration and Dielectric Temperature on Plasma Actuator Performance. In 49th AIAA Aerospace Sciences Meeting including the New Horizons Forum and Aerospace Exposition, Orlando, Paper Number AIAA2011-955, 2011.

[27] T. Segawa, H. Furutani, H. Yoshida, T. Jukes, and K.S. Choi. Wall normal jet under elevated temperatures produced by surface plasma actuator. In 45th AIAA Aerospace Sciences Meeting, Paper Number AIAA-2007-784, 2007.

[28] C.L. Enloe, T.E. McLaughlin, R.D. VanDyken, K.D. Kachner, E.J. Jumper, T.C. Corke, M. Post, and O. Haddad. Mechanisms and responses of a single dielectric barrier plasma actuator: geometric effects. AIAA Journal, 42(3):595-604, 2004.

[29] J.D. Kraus and K.R. Carver. Electromagnetics. Electrical Engineering Series. McGraw-Hill, 1973.

[30] A.H. Shapiro. The dynamics and thermodynamics of compressible fluid flow. Number v. 1-2. Ronald Press, 1953.

[31] I.H. Shames. Mechanics of fluids. McGraw-Hill series in mechanical engineering. McGraw-Hill, 2003.

[32] C.L. Enloe, T.E. McLaughlin, G.I. Font, and J.W. Baughn. Parameterization of temporal structure in the single-dielectric-barrier aerodynamic plasma actuator. AIAA Journal, 44(6):1127-1136, 2006.

[33] G. Nellis and S.A. Klein. Heat transfer. Cambridge University Press, 2009.

[34] R.J. Vidmar. Plasma cloaking: Air chemistry, broadband absorption, and plasma generation. Southwest Research Inst. Report, 1, 1990.

[35] J.R. Roth. Industrial plasma engineering: Applications to nonthermal plasma processing, volume 1. Taylor \& Francis, 2001.

[36] D.F. Opaits, S.H. Zaidi, M.N. Shneider, R.B. Miles, A.V. Likhanskii, and S.O. Macheret. Improving thrust by suppressing charge build-up in pulsed dbd plasma actuators. In 47 th AIAA Aerospace Sciences Meeting Including the New Horizons Forum and Aerospace Exposition, Paper Number AIAA-2009-487, 2009.

[37] J.W. Baughn, C.O. Porters, B.L. Peterson, T.E. McLaughlin, C.L. Enloe, G.I. Font, and 
C. Baird. Momentum transfer for an aerodynamic plasma actuator with an imposed boundary layer. In 44 th AIAA Aerospace Sciences Meeting and Exhibit, Paper Number AIAA 2006-168, 2006. 


\section{List of Figures}

1 Standard SDBD actuator configuration . . . . . . . . . . . . . . 18

2 Schematic of experimental set-up . . . . . . . . . . . . . . . 18

3 Traces of the input voltage (a) and actuator current (b) for different temper-

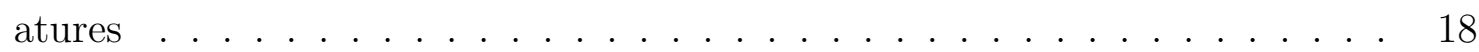

4 Side view of plasma created, (a) cold, (b) ambient, (c) hot cases . . . . . . . 19

$5 \quad$ Variation of power with applied voltage . . . . . . . . . . . . . . . . 19

6 Velocity contours and streamlines of cold (a), ambient (b), and hot (c) cases 20

7 U-component of velocity at $\mathrm{x}=$ : (a) $0 \mathrm{~mm}$, (b) $10 \mathrm{~mm}$, (c) $15 \mathrm{~mm}$, (d) $30 \mathrm{~mm} 21$

8 U-component (a) and V-component (b) of velocity at $\mathrm{y}=2 \mathrm{~mm}$ from the



9 Influence of temperature on the induced velocity . . . . . . . . . . . . 22 


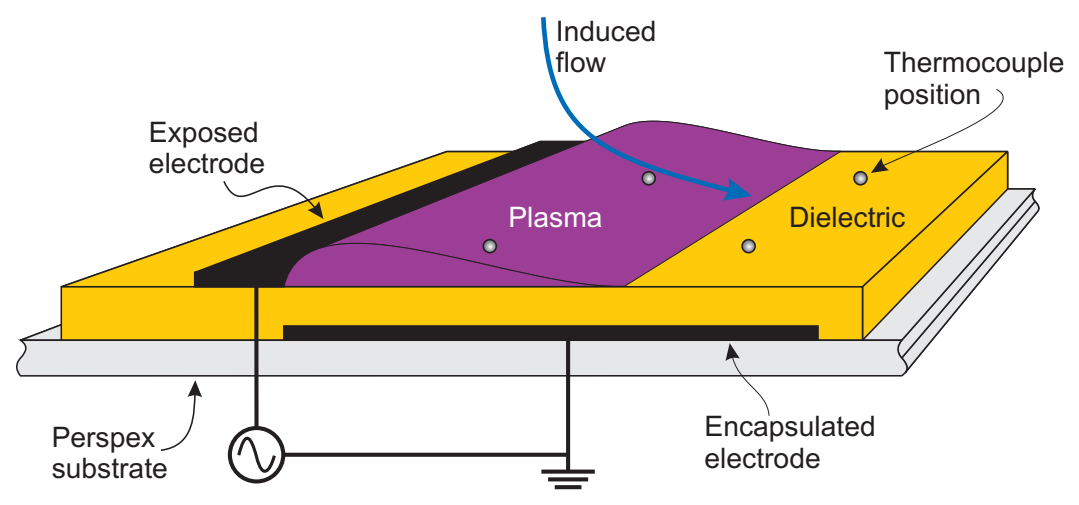

FIG. 1: Standard SDBD actuator configuration



FIG. 2: Schematic of experimental set-up
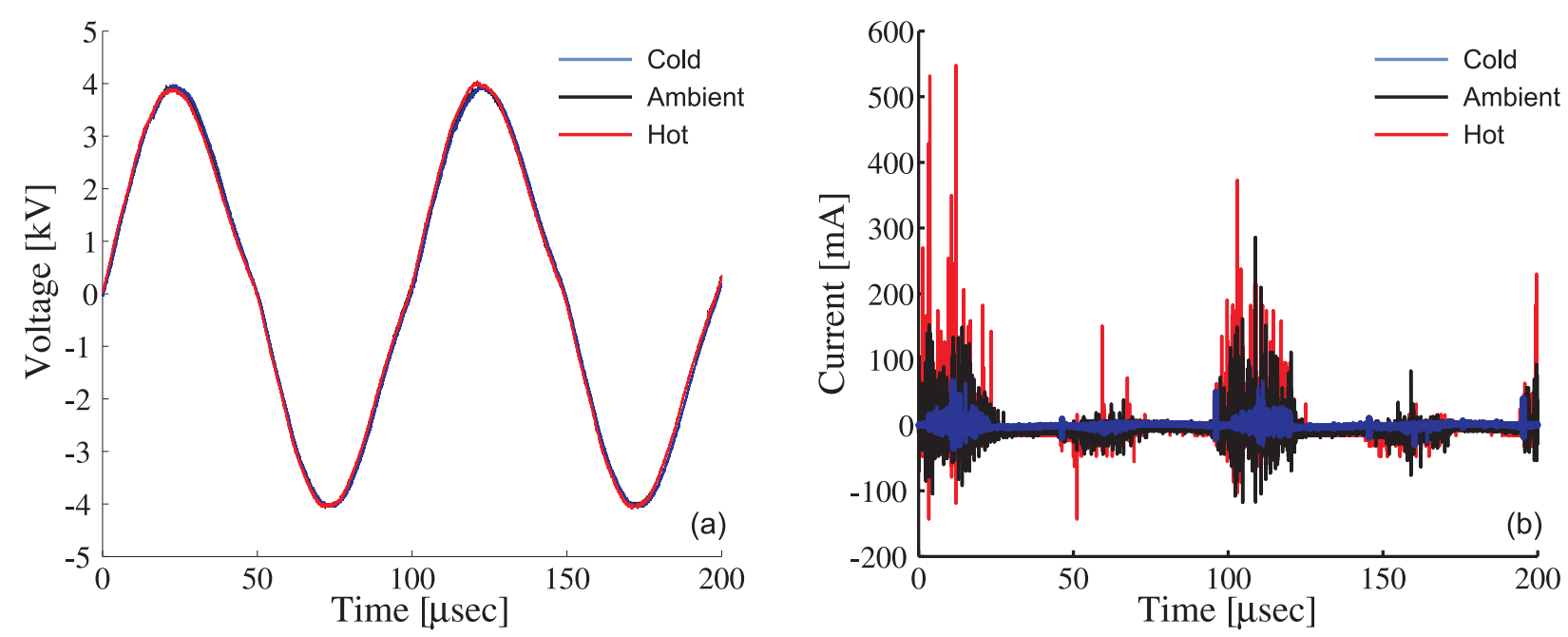

FIG. 3: Traces of the input voltage (a) and actuator current (b) for different temperatures 

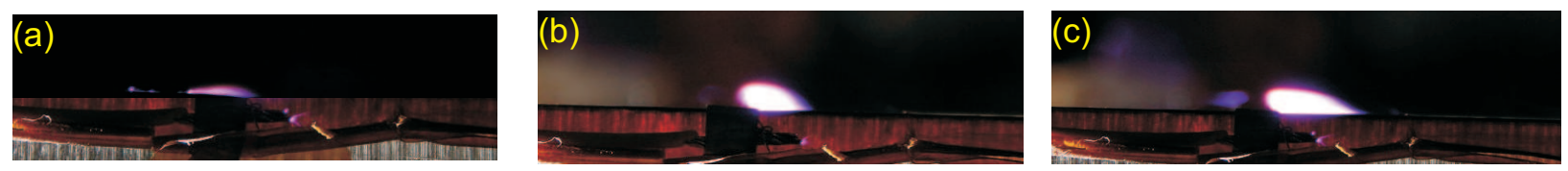

FIG. 4: Side view of plasma created, (a) cold, (b) ambient, (c) hot cases

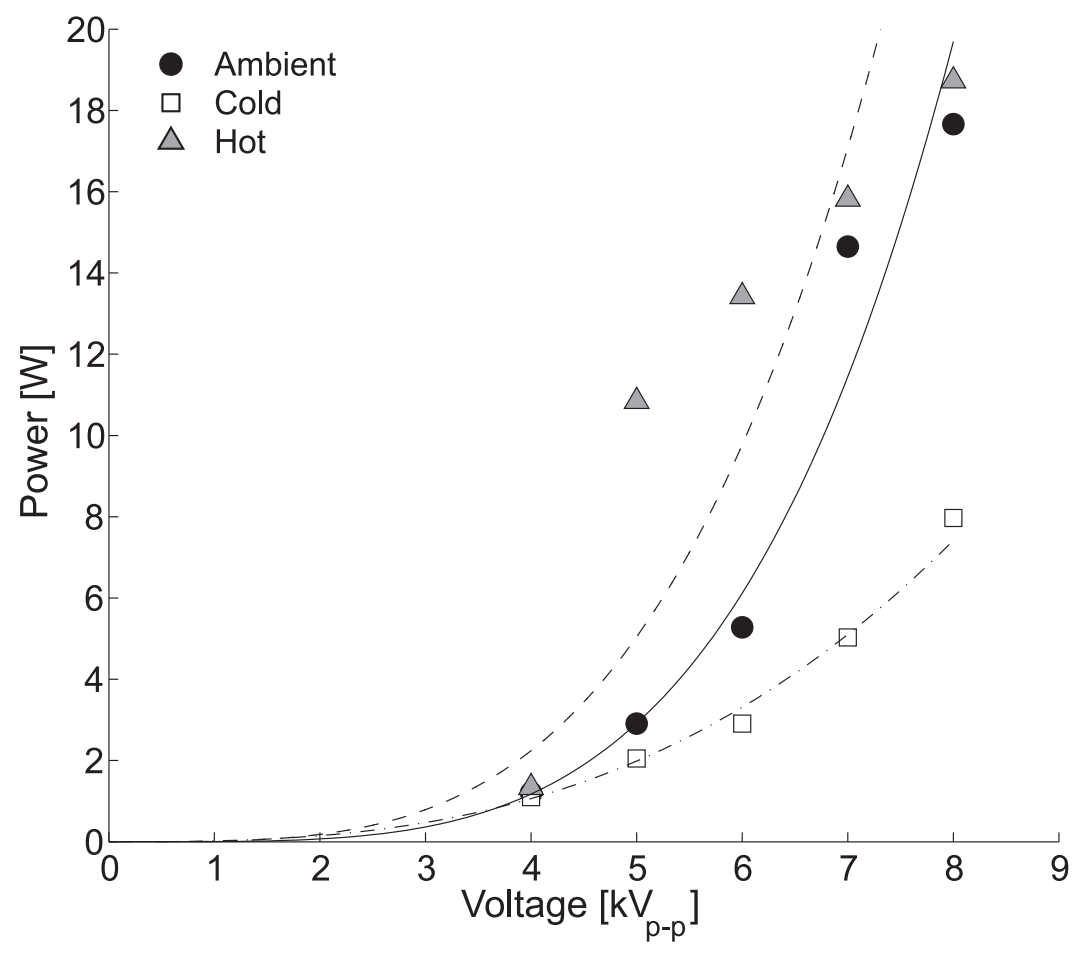

FIG. 5: Variation of power with applied voltage 

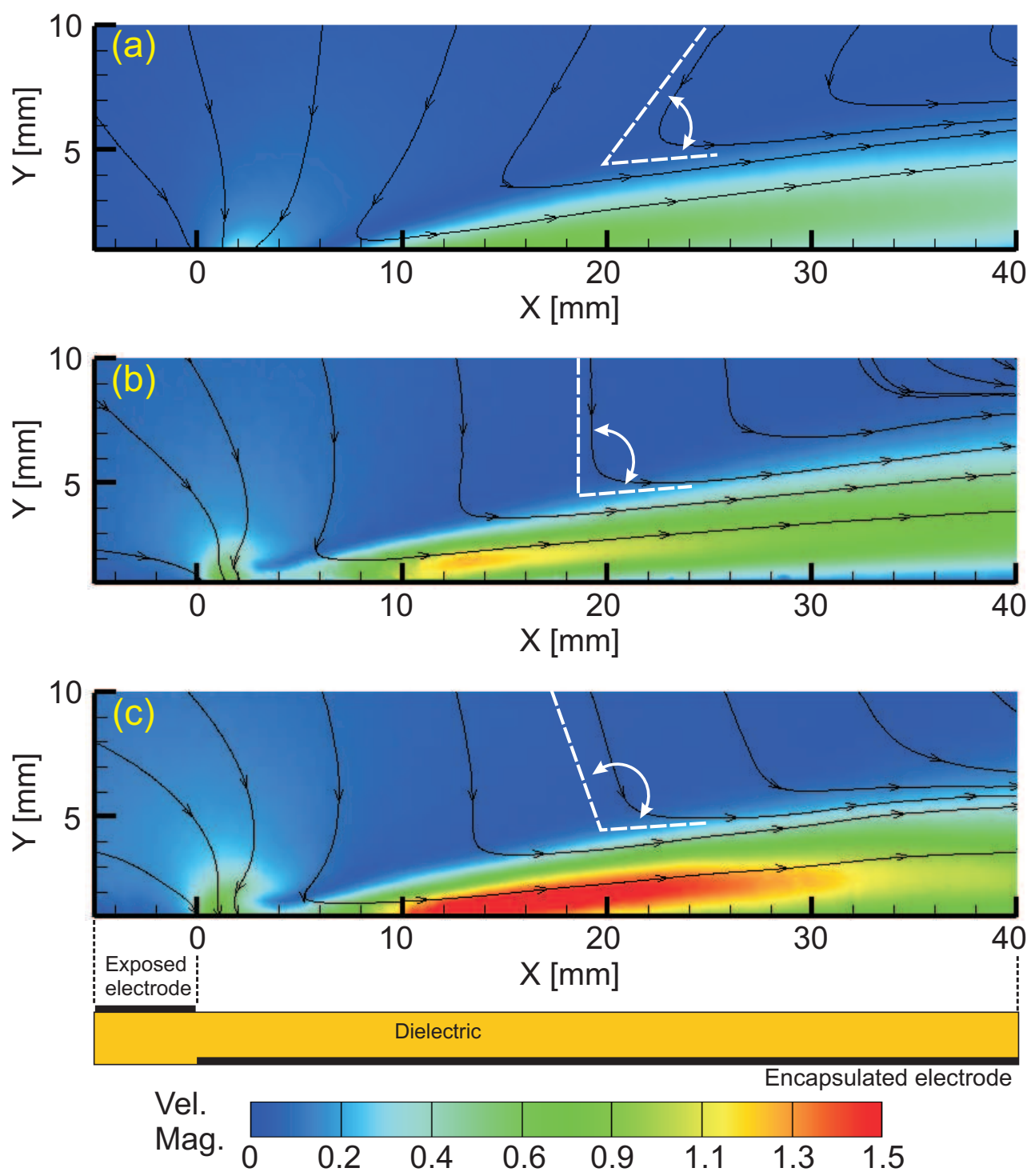

FIG. 6: Velocity contours and streamlines of cold (a), ambient (b), and hot (c) cases 

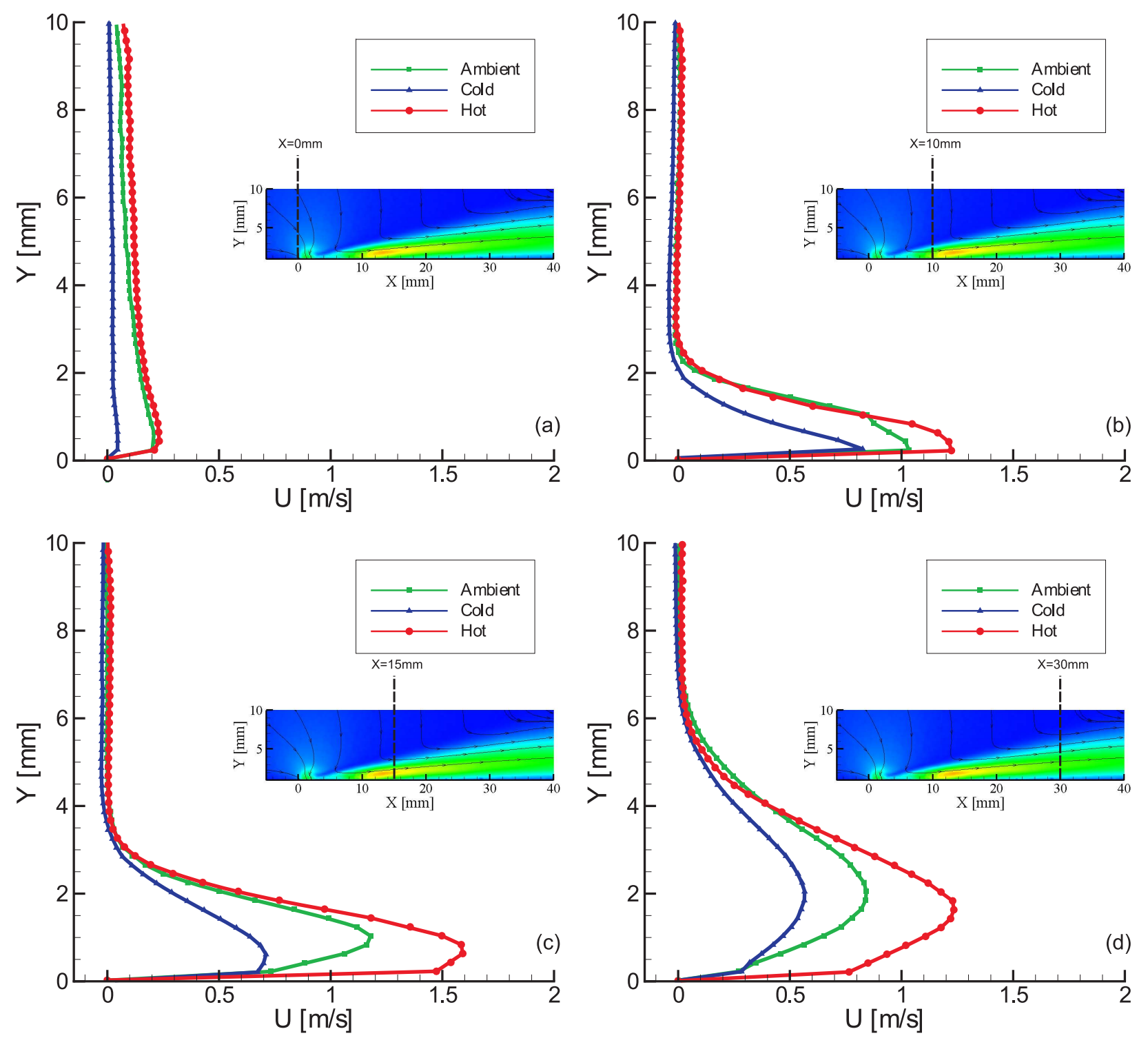

FIG. 7: U-component of velocity at $\mathrm{x}=$ : (a) $0 \mathrm{~mm}$, (b) $10 \mathrm{~mm}$, (c) $15 \mathrm{~mm}$, (d) $30 \mathrm{~mm}$ 

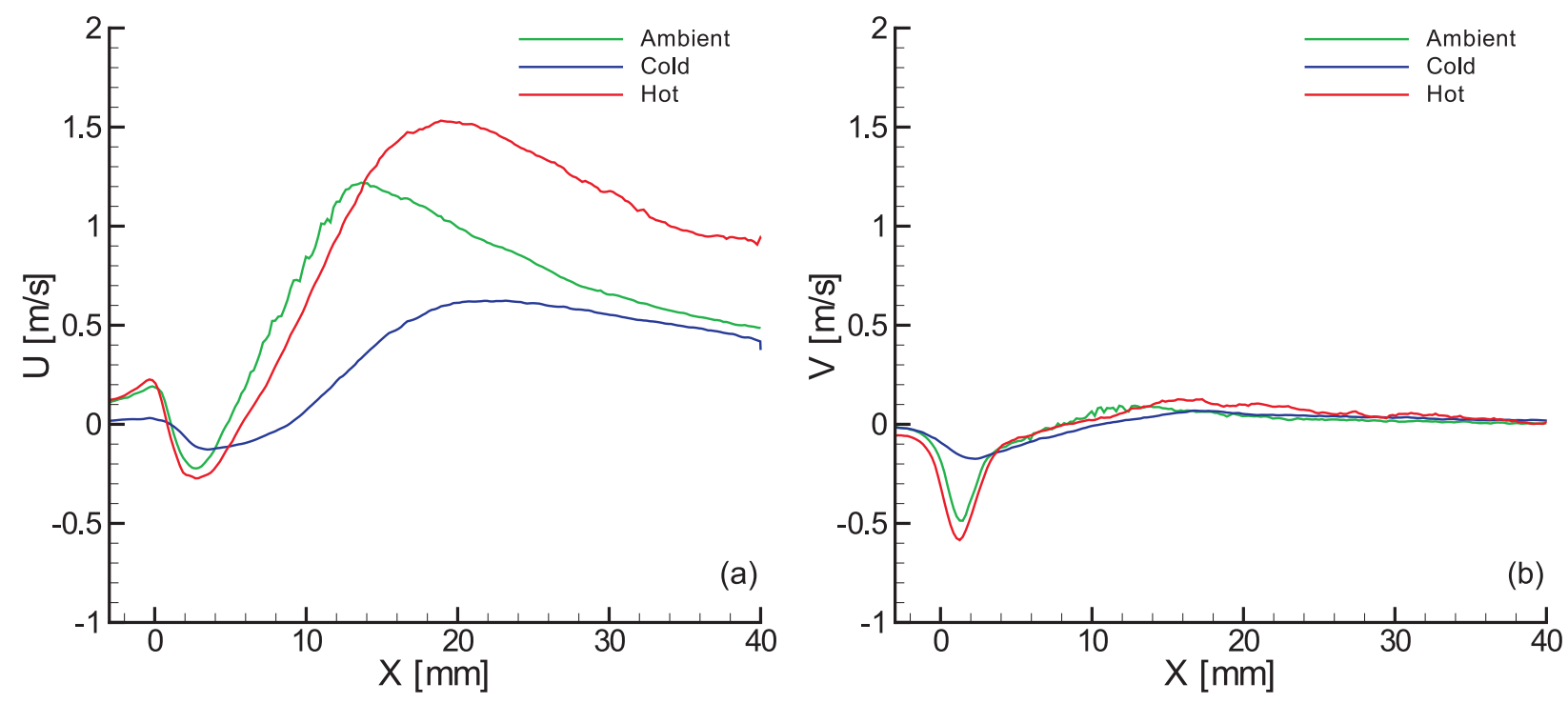

FIG. 8: U-component (a) and V-component (b) of velocity at $\mathrm{y}=2 \mathrm{~mm}$ from the surface

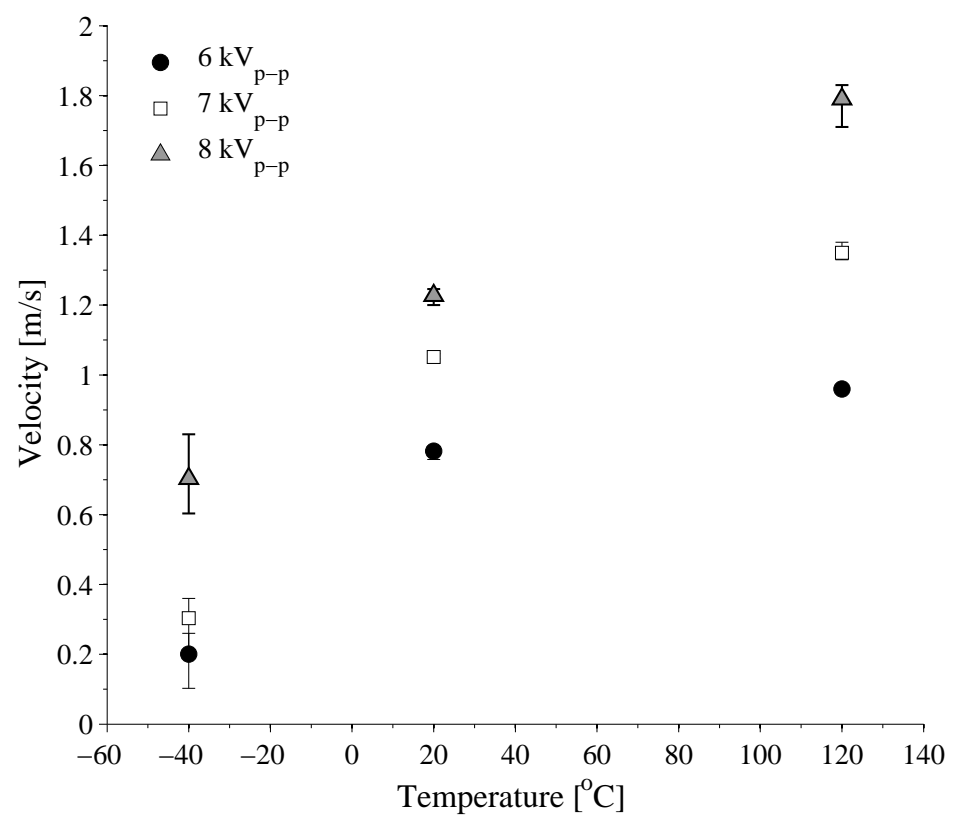

FIG. 9: Influence of temperature on the induced velocity 